\title{
DA ESCOLA ÚNICA À EDUCAÇÃO FRAGMENTADA: O CONGRESSO NACIONAL NA REFORMA DO ENSINO TÉCNICO
}

\author{
FROM THE SINGLE SCHOOL TO FRAGMENTED EDUCATION:THE NATIONAL CONGRESS IN \\ TECHNICAL EDUCATION REFORM
}

Jailson A. dos Santos 1

Resumo Este trabalho tem o objetivo de mostrar que as forças políticas do Congresso Nacional, em aliança com setores do poder Executivo, tornaram hegemônico o pensamento liberal-conservador no campo educacional. Dessa forma, construíram uma estratégia, a partir da qual conseguiram aprovar, em dezembro de 1996, a Lei de Diretrizes e Bases de característica generalista, particularmente no que se refere à educação profissional. Tal fato permitiu que a reforma do ensino técnico fosse regulamentada pelo decreto $\mathrm{n}^{\circ} 2.208 / 97$, originário do poder Executivo, promovendo, assim, a separação entre formação geral e formação específica nesta modalidade de ensino, jogando por terra a concepção de escola única que havia sido proposta no projeto original, inspirada nos educadores vinculados ao pensamento marxista no campo educacional. Palavras-chave escola única, ensino técnico; reforma; Congresso Nacional.
Abstract The purpose of this article is to show that the political forces in the National Congress, in alliance with sectors in the Executive, rendered the conservative liberal thought hegemonic in the educational field. As a result, they built a strategy based on which they were able to approve, in December 1996, the Guideline and Base Law, which is generalist in nature, particularly with regard to professional education. This fact allowed the technical education reform to be regulated via Decree \# 2.208/97, originating at the Executive, promoting, thus, the separation between general and specific education in this mode of teaching, undermining the single school concept that had been proposed in the original project, inspired in educators who are connected to the Marxist line of thought in the educational field.

Keywords single school; technical education; reforms; National Congress. 


\section{A tortuosa trajetória do ensino médio no Brasil: uma breve análise}

Na história da educação brasileira, quando o centro do debate está nas formas de organização da sua estrutura, um dos pontos mais conflitantes está na relação entre o ensino médio e o ensino técnico.

As tensões presentes nesta relação passaram a adquirir contornos nítidos a partir da década de 1940, período em que foi se consolidando o paradigma do desenvolvimento do capitalismo brasileiro fundado no avanço da industrialização.

É neste contexto que se efetivou a reforma do nosso sistema educacional, que, apesar de ter sido implementada gradativamente ${ }^{2}$, preservou, no ensino secundário, o princípio da dualidade representado, por um lado, pelas escolas responsáveis por ministrar o ensino secundário propedêutico destinado a promover a formação baseada no humanismo clássico e, por outro, pela criação de uma rede de ensino destinada à formação de técnicos, com o objetivo claro de formar contingentes de trabalhadores qualificados para atuar nas novas estruturas ocupacionais demandadas pela política de substituição de importações.

Além da dualidade, esta reforma apresentou um outro aspecto negativo no que se refere à estrutura criada para o ensino secundário nas suas duas modalidades: a falta de flexibilidade no ramo profissional, representada pela restrição do acesso ao ensino superior para os alunos egressos dos cursos técnicos.

O decreto-lei $\mathrm{n}^{\circ}$ 4.073, de 30 de janeiro de 1942, também denominado Lei Orgânica do Ensino Industrial, no que se refere à articulação do ensino industrial com as demais modalidades, estabelecia no seu artigo 18, inciso III que:

“É assegurada aos portadores de diploma conferido em virtude de conclusão de curso técnico a possibilidade de ingresso em estabelecimento de ensino superior, para matrícula em curso diretamente relacionado com o curso técnico concluído, verificada a satisfação das condições de preparo, determinadas pela legislação competente" (Brasil, 2006).

O princípio da interdição à entrada irrestrita aos cursos superiores, ao contrário do que ocorria com os concluintes do ensino secundário na sua vertente propedêutica, foi aplicado também aos alunos oriundos das outras modalidades do ramo profissional, como era o caso dos portadores de diplomas de técnico nas áreas comercial e agrícola e daqueles que possuíam a formação no curso normal 3 .

Durante os anos 50, os cursos técnicos foram adquirindo o mesmo status atribuído ao ensino secundário propedêutico. Nesta perspectiva, a 
partir da Constituição Federal promulgada em 1946, foi editado um conjunto de leis para valorizar o ensino técnico.

Inicialmente foi aprovada a lei $\mathrm{n}^{\circ} 1.076$, de 31 de março de 1950, a qual assegurava aos que concluíssem o primeiro ciclo do ensino industrial, comercial ou agrícola o ingresso no curso secundário (clássico ou científico), previsto no decreto-lei $n^{\circ} 4.244$ de 1942, desde que prestassem exame nas disciplinas não estudadas no primeiro ciclo da modalidade propedêutica.

Posteriormente, a lei $\mathrm{n}^{\circ} 1.821$, de 12 de março de 1953, conhecida como lei de equivalência, ampliou as medidas estabelecidas na lei $\mathrm{n}^{\circ} 1.076 / 50$, tendo em vista que, no seu art. $2^{\circ}$, inciso III, garantia o direito à matrícula em qualquer curso superior aos portadores de diplomas de técnico nos ramos industrial, comercial ou agrícola, desde que fossem devidamente aprovados em exame vestibular e cumprissem as exigências específicas para cada caso.

O enorme impulso tomado pelo crescimento do capitalismo industrial, que, na década de 1950, se encontrava na segunda fase de plena expansão no país ${ }^{4}$, propiciou a significativa reformulação, de ordem políticoadministrativo e pedagógica, nas estruturas dos cursos voltados para a formação de técnicos para atuar na atividade industrial.

É nesse contexto que começa a ser revisto o ensino técnico na vertente industrial, culminando com a aprovação da lei $\mathrm{n}^{\circ} 3.552$, de 16 de fevereiro de 1959, dispositivo que lhe conferiu uma nova organização das escolas federais, dando-lhes autonomia administrativa, financeira, pedagógica e técnica. No âmbito pedagógico, os vários cursos industriais básicos foram substituídos por um único curso, com uma estrutura curricular dotada de uma oferta maior de cultura geral e menor especialização, fazendo com que o ensino industrial apresentasse um curso básico mais próximo do ginásio secundário no ramo propedêutico.

Segundo Cunha (1998), as diferentes modalidades do segundo ciclo do ensino secundário, ao longo da década de 1950, assumiram progressiva função propedêutica, tendo em vista que as leis de equivalência e a própria Lei de Diretrizes e Bases (LDB), promulgada em 1961, foram eliminando as restrições à entrada dos alunos no ensino superior. Ao mesmo tempo em que esse processo se desenvolvia, as escolas técnicas industriais da rede federal passaram a se destacar pela qualidade, principalmente após a lei $\mathrm{n}^{\mathrm{o}}$ 3.552/59, que estabeleceu mecanismos para possibilitar a estreita articulação dos seus cursos com a produção. Entretanto, os cursos técnicos, nos ramos agrotécnico e comercial, e as escolas normais experimentavam a perda do prestígio, a falta de reconhecimento social, tendo em vista o baixo desempenho dos seus alunos.

Nos anos 50, além das mudanças que se concretizaram no ensino médio na sua modalidade profissional, principalmente no que se refere aos cursos 
no ramo técnico-industrial, também foram pensadas alterações estruturais para serem implementadas no secundário propedêutico, para o qual, segundo Amado (1973), desde 1956, as autoridades do Ministério da Educação vinham defendendo a necessidade de uma completa reformulação, propondo, inclusive, "a sua fusão (e não articulação de seus ramos)". Apesar destas iniciativas terem surgido no momento em que o projeto de lei de Diretrizes e Bases tramitava no Congresso Nacional, e as ações das autoridades do MEC caminhavam para uma proposta de unificação do ensino médio, concretamente, a LDB-61 avançou bem menos nessa direção.

Verifica-se, portanto, que no período situado entre a reforma proposta pelas leis orgânicas do ensino, na década de 1940, e a promulgação da Lei de Diretrizes e Bases em 1961 (lei nº 4.024/61), o máximo que se conseguiu foi assegurar a equivalência entre os diferentes ramos do ensino secundário, a despeito dos esforços de alguns setores do MEC em empreender ações para unificar a sua estrutura.

A ditadura militar, implantada com o golpe de março de 1964, estabeleceu um ciclo de reformas na educação, com o objetivo de ajustá-la ao projeto societário das frações de classe do capital que apoiaram a ordem sócioeconômica, a qual foi a responsável pela construção do Estado de Segurança Nacional.

Saviani (1988a), ao analisar o conjunto de reformas do ensino promovido no período dos governos militares, concluiu que a ruptura política imposta pelo golpe de 1964 foi uma exigência para a permanência da ordem sócio-econômica, e a continuidade desta se estendeu para os diversos setores de atividade do Estado, particularmente para a educação. Este aspecto se reflete na legislação, na medida em que a Lei de Diretrizes e Bases, promulgada em agosto de 1971 (lei $\mathrm{n}^{\circ} 5.692 / 71$ ), que instituiu o ensino de primeiro e segundo graus, preservou os objetivos da educação expressos na lei $\mathrm{n}^{\circ} 4.024 / 61$, aprovada em dezembro de 1961.

A lei $\mathrm{n}^{\circ}$ 5.692/71 modificou a estrutura do nível médio, convertendo-o em ensino de segundo grau profissionalizante e obrigatório, substituindo, dessa forma, a equivalência entre as vertentes profissional e propedêutica pela oferta de habilitação profissional ao final do curso. Entretanto, o ensino médio unificado, viés liberal da ditadura militar5, não conseguiu conciliar seus objetivos com as necessidades do mercado de trabalho, tampouco cumprir suas funções sociais proclamadas nos discursos oficiais: eliminar a segregação social e a diferença acentuada de status $^{6}$.

Tal fato se explica pela permanência da ordem capitalista, como vimos anteriormente, na medida em que ela é a responsável pela continuidade da segregação existente na sociedade, a qual se reflete na escola, a despeito de a reforma proposta pela lei $\mathrm{n}^{\circ} 5.692 / 71$ tentar estabelecer em todo o país um modelo único de ensino de segundo grau. 
Machado (1991), ao analisar o pensamento liberal no âmbito da educação, concluiu que a unificação escolar mascara o caráter diferenciador inerente à sociedade capitalista, já que o papel articulador/desarticulador deste pensamento pressupõe que as concepções definidas para a estrutura escolar do processo pedagógico e da administração educacional estão subordinadas à gerência do Estado capitalista, bem como à lógica empresarial.

Esta perspectiva nos permite compreender o fracasso do ensino médio unificado, na medida em que este, sob a gestão do Estado de Segurança Nacional, não conseguiu eliminar as desigualdades, como proclamavam os apologistas da reforma educacional, apesar das mudanças impostas ao longo da sua trajetória, como foi o caso da instituição do parecer $\mathrm{n}^{0} 76 / 75$ - editado em substituição ao parecer $n^{\circ} 45 / 72$, que implantou um novo conceito de habilitação, com o surgimento das habilitações básicas, e, dessa maneira, modificou a estrutura do ensino de segundo grau profissionalizante - e da promulgação da lei $\mathrm{n}^{\circ} 7.044$, de 18 de outubro de 1982, que eliminou a compulsoriedade da profissionalização no ensino médio, tendo em vista a pressão, dentre outros atores sociais, das próprias autoridades do MEC e dos secretários de Educação dos estados.

Os remendos na estrutura de ensino médio unificado proposto pela lei $\mathrm{n}^{0}$ 5.692/71 foram feitos com o objetivo de sanar as dificuldades encontradas pelas escolas de implantar a profissionalização, tendo em vista, principalmente: os escassos recursos financeiros para cobrir os gastos elevados com a profissionalização; a falta de pessoal docente qualificado; a carga horária reduzida na parte de educação geral; a incompatibilidade entre a quantidade de técnicos formados pelas escolas da rede pública e as reais necessidades do mercado de trabalho; e a aspiração da clientela, que na sua grande maioria tinha o objetivo de ingressar no ensino superior.

As medidas tomadas pelas autoridades do setor educacional não foram suficientes para reparar o fracasso das políticas voltadas para as escolas secundárias, impostas pelo Estado de Segurança Nacional, principalmente para a rede pública de ensino. Segundo afirma Machado (1991), as tentativas de implementar políticas de escola única, como foi o caso do ensino de segundo grau profissionalizante e compulsório, tiveram como resultado a continuidade das escolas que ofereciam saberes diferenciados. Esse fator, inerente às sociedades de classes, impede que seja eliminada a dicotomia entre as modalidades profissional e propedêutica, historicamente presente na estrutura do ensino secundário. 


\section{A reforma do ensino médio no Congresso Nacional: da tentativa de unificação à educação desintegrada}

Todo o movimento que marcou o processo de implantação do ensino de segundo grau profissionalizante produziu sobre ele uma dinâmica própria, identificada a partir do debate que envolve a relação entre educação e trabalho.

Isto se deveu às características peculiares deste nível de ensino, cuja função, entre outras, era atender a adolescentes na faixa etária dos 15 aos 19 anos, que, ao concluírem o curso, dependendo das suas aspirações e, principalmente, do nível sócio-econômico, ou iam disputar uma vaga na universidade, ou iam competir no mercado de trabalho. Cabe observar que grande parte desses jovens, mesmo antes de terminar o segundo grau, já estava inserida no setor produtivo.

É com base nesta perspectiva que se desenvolveu uma grande polêmica em torno da controvertida profissionalização no ensino de segundo grau, que teve início na segunda metade da década de 1970 e atravessou os anos 80. Nesta disputa estava em jogo a relação entre a sociedade, o trabalho e a escola de segundo grau.

Arroyo (1988), ao analisar a questão, afirma que o debate em torno do vínculo entre ensino secundário e o mundo do trabalho, no período acima referido, parecia unir diversas correntes do pensamento educacional brasileiro, as quais, a partir desta relação, buscavam concretizar um projeto capaz de estruturar a escola de nível médio. Entretanto, as divergências se explicitaram quando foram pensadas as concepções que os diferentes segmentos da sociedade tinham a respeito do trabalho e da produção; do ato educativo e, sobretudo, a própria concepção de educação de nível médio.

Foram essas divergências que levaram à polarização das disputas entre duas correntes do pensamento educacional brasileiro: de um lado, aqueles que se fundamentavam nos pressupostos teóricos da proposta liberalconservadora; do outro, a corrente que, baseada na concepção marxista, defendiam a tese da escola única, fundada no trabalho como princípio educativo e na formação integral do homem.

Machado (1991), com base nas análises feitas por Mario Alighiero Manacorda7, mostrou uma distinção fundamental entre a escola única, fundamentada na perspectiva marxista e aquela que é pensada a partir da concepção liberal. No caso da primeira, além da universalidade, da laicidade, da gratuidade e das modificações curriculares, as quais se processam com a incorporação das disciplinas científicas, um outro postulado deve ser acrescentado: a união da instrução com o trabalho. Já no âmbito do pensamento liberal, a relação entre trabalho e escola se estabelece de diferentes formas, 
ao se explicitar como sendo: recurso didático; valor moral do trabalho; ou modelo de formação cujo objetivo está centrado no ingresso imediato no mercado de trabalho.

É esse processo de disputa, ocorrido entre o pensamento marxista e a corrente liberal, que presidiu o debate em toda a trajetória da Lei de Diretrizes Bases no âmbito do Congresso Nacional. Isto se deveu ao fato de que o objetivo de cada uma dessas correntes era tornar hegemônica a sua própria concepção político-filosófica de educação e, dessa maneira, estabelecer os princípios básicos da reforma do ensino médio. Em decorrência, operar as mudanças nas formas de organização das escolas técnicas.

No primeiro momento de tramitação da Lei de Diretrizes Bases na Câmara dos Deputados, o projeto original, de autoria de Octávio Elísio, reproduziu na íntegra a concepção defendida pela corrente de educadores que, na conjuntura do final da década de 1980 e no curso dos anos 90, atuava na Academia, tendo na figura de Dermeval Saviani8 uma de suas mais destacadas expressões. Ele foi, inclusive, o responsável pela elaboração de uma proposta de LDB, fundamentada na teoria marxista, a qual foi debatida e devidamente aprovada na XI Reunião Anual da Associação Nacional de PósGraduação e Pesquisa em Educação (Anped), realizada em Porto Alegre (RS), entre 25 e 29 de abril de 1988, sob o tema Em Direção às Novas Diretrizes e Bases da Educação Brasileira.

É nesta perspectiva que o Projeto de Lei da Câmara (PLC) n ${ }^{\circ} 1.258 / 88$, na sua origem, propõe no seu artigo 16 que

"A educação fundamental abrange o período correspondente à faixa etária dos zero aos dezessete anos e tem por objetivo geral o desenvolvimento omnilateral [grifos do autor] dos educandos de modo a torná-los capazes de participar ativamente da sociedade" (Brasil, 1989, p. 90).

Com relação ao ensino de segundo grau, especificamente, o artigo 35 do referido projeto estabelece que a educação escolar

“(...) será ministrada apenas na língua nacional e tem por objetivo geral propiciar aos adolescentes a formação politécnica [grifos do autor] necessária à compreensão teórica e prática dos fundamentos científicos das múltiplas técnicas utilizadas no processo produtivo"' (Brasil, 1989, p. 90).

Frigotto (1988) e Saviani (1988b), ao explicitarem as bases sobre as quais deveriam se assentar a educação escolar, afirmavam que o então ensino de segundo grau teria de se estruturar a partir da relação entre educação e trabalho, dentro da perspectiva politécnica, o que significava estabelecer um modelo de formação através do qual os alunos seriam capazes de articu- 
lar teoria e prática e, em decorrência, de dominar os fundamentos das diferentes técnicas utilizadas no setor produtivo moderno, além de se tornarem cidadãos conscientes politicamente e capazes de se integrarem na tarefa da transformação social.

A politecnia, portanto, se funda numa concepção omnilateral, segundo a qual o homem não se reduz ao trabalho produtivo material. Inclui também o trabalho em outras dimensões, isto é, a arte, a estética, a poesia e o lazer, o que, em outras palavras, significa a entrada do homem no mundo da liberdade.

Uma das principais condições para desenvolver uma prática pedagógica fundada na politecnia como eixo estruturador dos currículos do ensino de segundo grau, em todo o sistema educacional do país, era reorganizar a rede de escolas, dotando-a de equipamentos necessários, de modo a proporcionar ao educando uma formação que articulasse teoria e prática, e, em decorrência, capacitá-lo para a compreensão das diferentes técnicas utilizadas no processo produtivo.

É com base nesta condição que o PLC n ${ }^{\circ} 1.258 / 88$ previu, no seu artigo 37 e no parágrafo único do mesmo, que

“Os currículos das escolas de $2^{\circ}$ grau abrangerão, obrigatoriamente, além da língua nacional, o estudo teórico-prático das ciências e da matemática, em íntima vinculação com o trabalho produtivo. (...) As escolas de $2^{\circ}$ grau disporão de oficinas práticas organizadas preferencialmente como unidades socialmente produtivas" (Brasil, 1989, p. 90).

É importante ressaltar que há na autoria do PLC $\mathrm{n}^{\circ} 1.258 / 88$ uma controvérsia, no mínimo curiosa, e que até o momento não temos dados para firmar uma posição sobre a mesma. Trata-se de entender de que forma se processou a articulação política entre setores da sociedade e a Casa Legislativa, no sentido de dar ao deputado Octávio Elísio a prerrogativa de apresentar o projeto de LDB, baseado em Marx, para reformular o ensino de segundo grau, mesmo estando esse parlamentar filiado ao Partido da Social Democracia Brasileira (PSDB), agremiação política alinhada à ideologia de centro-direita.

Cabe aqui destacar que nessa legislatura, embora em número reduzido, havia na Câmara dos Deputados parlamentares eleitos por partidos considerados de esquerda, que, inclusive, no decorrer da tramitação da LDB, conforme mostrou Santos (2006), apresentaram nesta mesma Casa projetos de LDB com o mesmo corte ideológico do projeto original, como foi o caso da deputada Lídice da Mata, do Partido Comunista do Brasil (PCdoB), da Bahia, a qual em junho de 1989 teve a iniciativa de apresentar o PLC $\mathrm{n}^{\circ}$ 2.784/89 de LDB. 
Na literatura produzida no campo da ciência política, vários autores constataram que as votações dos diferentes grupos das bancadas partidárias, nas diversas matérias apresentadas nas casas legislativas, eram compatíveis com as suas respectivas posições ideológicas, significando, dessa forma, que havia um padrão de coalizão consistente, o qual se justifica a partir da visão de mundo dos parlamentares. Tal aspecto torna-se responsável pela construção de uma identidade de pensamento entre os parlamentares. É esta constatação que nos permite distribuir os partidos num continuum ideológico, segundo a classificação adotada usualmente, em direita, centro e esquerda, na medida em que as legendas situadas num mesmo bloco ideológico votam de modo similar.

Tomando por base essa distribuição partidária, segundo o corte ideológico, o qual norteia a ação dos parlamentares, Santos (2006) mostrou que, durante o período de tramitação da LDB no Congresso Nacional9 (19881996), a posição centro-direita foi hegemônica nas duas casas legislativas, e foi ela que definiu as mudanças radicais feitas com o objetivo de reorientar as concepções expressas no projeto original.

A pressão pela reorientação do que estava expresso no PLC n ${ }^{\circ} 1258 / 88$, por parte das forças políticas de centro-direita, influenciou decisivamente o substitutivo do deputado Jorge Hage, do Partido Democrático Trabalhista (PDT), da Bahia, cujo conteúdo desmantelou parcialmente o projeto original de LDB, ao cortar uma das pernas que sustentava a concepção de educação básica: a formação omnilateral, na qual, como vimos anteriormente, se fundava a politecnia.

No que se refere à formação técnico-profissional, esse substitutivo abria um flanco para a concomitância externa, isto é, a possibilidade de o aluno cursar, ao mesmo tempo, o ensino médio e a educação profissional de nível técnico, em duas instituições diferentes, pois, segundo o seu artigo 56,

“O aluno matriculado ou egresso do ensino médio, (...) deverá contar com a possibilidade de acesso a uma formação técnico-profissional [grifos do autor] específica que não substitua a educação regular e contribua para o seu desenvolvimento como cidadão produtivo, proporcionando-lhe meios para prover sua existência material" (Brasil, 1991, p.12).

A perspectiva de separação entre o ensino médio e o ensino técnico, mais precisamente entre a formação geral e a formação profissional, no âmbito do substitutivo de Jorge Hage (PDT-BA), esvaziou a proposta do modelo educacional baseado nos pressupostos da escola única, concebida por Antonio Gramsci10, tendo em vista que tal separação, fatalmente, levaria à preservação da velha dualidade que, historicamente, estava incorporada à estrutura do ensino médio no Brasil. 
As alterações explicitadas no substitutivo do deputado Jorge Hage tiveram apoio integral dos setores que representavam as forças políticas de centro. Tal apoio se manifestou pelos secretários de Educação dos oito estados que passaram a ser governados pelo Partido do Movimento Democrático Brasileiro (PMDB), após as eleições de 1990. Estas autoridades, reunidas em Brasília, em 24 de maio de 1991, no gabinete do líder do PMDB na Câmara dos Deputados, Genebaldo Correia (PMDB-BA), tiraram uma posição conjunta, com o objetivo de

“(...) apoiar o documento [substitutivo de Jorge Hage] como está proposto, [grifos do autor] por entendê-lo nas atuais circunstâncias que atravessa o País, nos seus aspectos econômico, social e político, capaz de responder à maioria dos anseios da sociedade civil brasileira, cujos segmentos mais autênticos foram ouvidos ao longo da discussão da importante matéria, nos últimos dois anos.

Os representantes dos governos estaduais do PMDB assim resolvem, por julgar o texto aprovado pela Comissão de Educação, com a maioria dos votos do Partido, a ser submetido ao Plenário do Congresso Nacional, como representativo de avanços e conquistas obtidos pelo povo brasileiro e sempre defendidos pelo Partido" (Brasil, 1991, p. 5.057-8).

O desmantelamento do projeto original de LDB foi se intensificando na medida em que, durante o complexo processo de sua tramitação, a hegemonia da concepção liberal foi se consolidando no Congresso Nacional. Tal fato ficou muito nítido a partir do momento em que se materializou a disputa entre dois projetos de LDB. De um lado, o de autoria do senador Darcy Ribeiro, eleito pelo PDT no Rio de Janeiro, que, com a co-autoria dos senadores Marco Maciel, do Partido da Frente Liberal (PFL), e José Goldemberg, do PMDB, deu entrada no Senado Federal num outro Projeto de Lei de Bases, para tramitar em paralelo com o PLC $n^{\circ} 1.258$; do outro lado, o projeto original, agora tramitando com as modificações feitas pelo substitutivo do deputado Jorge Hage.

Darcy Ribeiro, já na campanha para o Senado Federal, em 1990, se colocava como o principal protagonista da elaboração de um novo projeto de LDB, o qual, segundo ele próprio, seria o instrumento capaz de garantir uma educação que viesse atender às classes desfavorecidas.

Entretanto, ao assumir o cargo de senador, Darcy Ribeiro esqueceu-se de levar em conta que, ao fazer alianças com os setores mais conservadores do Congresso Nacional, mais precisamente com aqueles que representavam os interesses das classes fundamentais, na realidade estava trabalhando para a manutenção do status quo, que era o de reafirmar o projeto 
educacional do setor liberal-conservador, em decorrência negar uma educação pública que viesse a emancipar os setores subalternos da nossa sociedade.

A entrada em cena do Projeto de Lei do Senado Federal (PLS) $\mathrm{n}^{\circ} 67$ alterou, significativamente, a correlação de forças que se constituiu em torno do debate e das negociações que estavam sendo realizadas para a definição do projeto original, tendo em vista que a grande maioria dos parlamentares vinculados ao PDT passou a apoiar o projeto de LDB de Darcy Ribeiro e, dessa maneira, esvaziou ainda mais as pretensões de se ter uma lei que expressasse, minimamente, uma concepção progressista no campo da educação, principalmente no que tange ao ensino médio.

A disputa entre esses dois projetos teve o seu desfecho no início do governo Fernando Henrique Cardoso, que, ao assumir o poder em janeiro de 1995, construiu uma forte articulação entre as forças políticas que atuavam no Executivo e no Legislativo. Tais forças se caracterizavam por apresentar uma coesão jamais vista ao longo de seis anos de história de tramitação da LDB no Congresso Nacional, cujo objetivo era conformar a lei de diretrizes e bases da educação às concepções do pensamento liberal.

Nesta nova fase de tramitação da LDB, Darcy Ribeiro passou a ter uma atuação ainda mais destacada, ao apoiar irrestritamente o então ministro da Educação Paulo Renato de Souza.

Cabe ressaltar que, embora o PDT estivesse na oposição ao governo de Fernando Henrique Cardoso, no âmbito das propostas para a definição da lei de diretrizes e bases, o senador Darcy Ribeiro, bem como a maioria dos parlamentares do seu partido se alinhava às estratégias traçadas pelas autoridades do MEC, expressas no Planejamento Político Estratégico 1995/1998, que apontava para a aprovação de uma lei de diretrizes e bases simplificada e generalista.

Tal estratégia tinha a finalidade de possibilitar a regulamentação, através de decretos e portarias, dos fundamentos das políticas de educação que na LDB se explicitavam de modo genérico. Dessa maneira, os princípios que norteariam a educação, em todos os seus níveis, estariam nos dispositivos instituídos a partir da LDB.

Este fato ficou muito claro no documento Memorando sobre o Projeto de Lei de Diretrizes e Bases da Educação Nacional, expedido pelo senador Darcy Ribeiro, em que fez pesadas críticas ao PLC $n^{\circ} 1.258$, que já estava tramitando no Senado Federal, chegando a ponto de relatar, nesse documento, que o projeto mantinha a mesma fisionomia do de 1988, e que o "seu caráter prolixo e exageradamente regulamentador" contrastava com leis de educação que haviam sido aprovadas em países como Espanha, Portugal, Colômbia, Argentina e Bolívia, os quais, segundo ele, "procuraram se adequar aos tempos modernos, por meio de leis sucintas". 
A estratégia adotada para que esse objetivo fosse atingido foi a utilização de artifícios regimentais, existentes no espaço do Legislativo, para modificar o curso do projeto de LDB oriundo da Câmara dos Deputados que, naquele momento, tramitava no Senado Federal. Para que esta ação obtivesse êxito, a proposta era a de que, ao apreciar a matéria nas comissões, ali fossem operadas profundas transformações, no sentido de ajustá-la às concepções do MEC e, em seguida, fazer com que o mesmo fosse votado no plenário do Senado Federal, para seguir o seu trâmite normal até a sanção do presidente da República.

Foi nesse quadro de articulações e tramas entre forças políticas que o senador Beni Veras (PSDB-CE), com base no art. 255, inciso II, letra “ $\mathrm{c}^{\text {" , }} \mathrm{n}^{0}$ 12 do Regimento Interno do Senado Federal, requereu, em 16 de fevereiro de 1995, junto à Mesa Diretora da Casa, que o PLC n ${ }^{\circ} 1.258 / 88$ passasse a ser identificado pelo número 101/93 e, além do despacho inicial, fosse também apreciado pela Comissão de Constituição Justiça e Cidadania.

Esse requerimento foi decisivo para conformar o projeto de LDB aos objetivos definidos pelo MEC, tendo em vista que a sua aprovação em plenário, obrigatoriamente, fazia com que a matéria recebesse o parecer do senador Darcy Ribeiro, o qual era na época o relator do projeto de lei de Diretrizes e Bases na Comissão de Constituição Justiça e Cidadania do Senado Federal.

Observa-se, portanto, que se fechou uma circunferência em torno do projeto de LDB. Pelo fato de Fernando Henrique Cardoso, no seu governo de coalizão, ter a grande maioria dos votos no Congresso Nacional, quer no plenário, quer nas comissões permanentes, o giro desta circunferência sempre conformava os seus pontos numa mesma posição: a dos interesses das forças políticas liberal-conservadoras.

Tal fato se confirmou na seção plenária do Senado Federal do dia 8 de março de 1995, quando o requerimento foi submetido à votação, e o resultado final apontou 43 votos a favor, 12 contra e uma abstenção, a do combativo senador Jefferson Perez (PDT-AM), cuja posição ambígua pode ter sido tomada para tentar ser coerente com as posições que vinha adotando no Senado Federal, contra as proposições de Fernando Henrique Cardoso, e ao mesmo tempo não se colocar totalmente contra os interesses de uma das figuras mais importantes do seu partido. Com a aprovação do requerimento, estavam dadas as condições favoráveis para que os objetivos do MEC, em termos de projeto de LDB, fossem plenamente satisfeitos.

Assim é que o substitutivo ao PLS n ${ }^{\circ} 101 / 93$, de autoria do senador Darcy Ribeiro, foi aprovado também na Comissão de Educação do Senado Federal, a qual era presidida pelo senador Roberto Requião (PMDB-PR), com a oposição dos senadores Esperidião Amin, do Partido Progressista Reformador (PPR), de Santa Catarina, Lauro Campos, do Partido dos Traba- 
lhadores (PT), do Distrito Federal, e Emília Fernandes, do Partido Trabalhista Brasileiro (PTB), do Rio Grande do Sul.

Estes parlamentares de oposição acusaram o governo de pressionar a comissão para aprovar o substitutivo, com o argumento de que as autoridades do Executivo, vinculadas ao MEC, ignoraram as longas negociações havidas entre o Fórum Nacional em Defesa da Escola Pública e os parlamentares que tratavam da matéria na Câmara.

Um dia após a votação favorável do substitutivo Darcy Ribeiro ao PLS n ${ }^{\circ}$ 101/93 na Comissão de Educação do Senado Federal, o ministro Paulo Renato enviou um telegrama, agradecendo-lhe pela participação ativa naquela seção, cujo teor era o seguinte:

“(...) dirijo-me a Vossa Excelência para manifestar os meus melhores agradecimentos pelo seu voto, na Comissão de Educação de Casa Legislativa, em cuja seção foi aprovado o projeto de lei da Câmara $n^{\circ}$ 101/93, que fixa as Diretrizes e as Bases da Educação Nacional - LDB, antigo anseio da comunidade (...) e que trará inúmeros benefícios para a sociedade" (Souza, 1995).

Este telegrama mostra a perfeita coesão da articulação feita entre o Executivo e o Legislativo. A partir daí, todo o movimento vai ser no sentido de manter a essência do substitutivo do senador Darcy Ribeiro, sobretudo naquilo que se referia ao ensino médio e à educação profissional, pois, nestas modalidades, verifica-se que o substitutivo se conformou às diretrizes políticas definidas pelo governo de Fernando Henrique Cardoso.

É nesse quadro que o projeto de LDB retornou à Câmara, onde tramitou durante todo o ano de 1996, até que, na seção do dia 17 de dezembro, foi submetido à votação e, ao final dos trabalhos da seção presidida pelo deputado Luis Eduardo Magalhães (PFL-BA), a Mesa anunciou a votação: dos 427 parlamentares ali presentes, 350 disseram 'sim' ao projeto de LDB, 73 votaram 'não' e quatro se abstiveram.

Logo após essa seção da Câmara dos Deputados, que passou a fazer parte da história da educação brasileira, o projeto de LDB foi remetido ao presidente Fernando Henrique Cardoso, que o sancionou no dia 20 de dezembro de 1996, convertendo-o em dispositivo legal, nascendo a partir daí a lei $\mathrm{n}^{\circ}$ 9.394, que fixava as diretrizes e as bases da educação nacional, e que levou o nome de Lei Darcy Ribeiro.

\section{Considerações finais}

Ao longo deste trabalho procuramos mostrar a forma pela qual se desenvolveu a estrutura do ensino médio em nosso país. No âmbito da tramitação da LDB no Congresso Nacional, o que constatamos foi a tentativa da cor- 
rente alinhada ao pensamento marxista no campo da educação de garantir, no espaço legislativo, a hegemonia das suas concepções para fundamentar as bases do ensino médio no Brasil. O próprio projeto original de LDB, como vimos anteriormente, confirma esta tese.

Entretanto, o processo de disputa no Congresso Nacional colocou limites para a referida posição, a qual, a despeito da luta política durante todo o processo, sempre levou desvantagem na correlação de forças com o segmento representativo da ideologia de centro-direita, que, conforme as análises desenvolvidas ao longo desse texto, mostramos que esta foi hegemônica durante todo o período de tramitação da lei nas duas casas legislativas.

A hegemonia da concepção liberal no campo da educação acabou desfigurando o projeto original, pelo menos no que se refere à proposta de ensino médio unificado, fundado na concepção da politecnia. E, mais grave ainda, através de manobras internas, os parlamentares, na sua maioria, alinhados ao corte ideológico liberal, aprovaram uma LDB que, devido ao seu caráter generalista, permitiu a regulamentação por decreto de toda a educação profissional, sobretudo do ensino técnico.

A edição do decreto $\mathrm{n}^{\circ} 2.208$ em abril de 1997, portanto logo após a promulgação da LDB (lei no 9.394/1996), introduziu um modelo de ensino técnico cuja estrutura, ao contrário do que previa o projeto original, era desintegradora, na medida em que, além de estar voltada para a preparação para o mercado de trabalho, previa a separação entre formação técnica e formação profissional na mesma instituição escolar.

Gramsci (1991), ao analisar a divisão do sistema educativo italiano, que ocorreu a partir do desenvolvimento da base industrial, concluiu que esta cisão obedeceu a um esquema racional, o qual se restringe à separação entre a escola clássica e a profissional, esta na modalidade técnica. A primeira, com o objetivo de propiciar a educação da futura classe dirigente, cujo princípio de orientação concreta estava baseado na cultura geral, fundada no humanismo clássico; a segunda, criada pela necessidade de se formar um novo 'intelectual urbano', oriundo das classes dominadas, para o exercício das novas profissões no âmbito da produção.

Dez anos após o início da reforma do sistema educativo brasileiro, verifica-se que o projeto encontra-se num estágio avançado de consolidação. Cabe, então, levantar a seguinte questão: até que ponto será possível, dentro dos marcos de um regime capitalista, com as características que temos no Brasil, construir um projeto de ensino médio fundado na concepção da politecnia, o que em outras palavras significa caminhar para uma escola única, que, na concepção gramsciana, deve equilibrar a relação entre formação geral e formação técnica. 
Se essa utopia é atingível, o que fazer para que se tenha a hegemonia da concepção da politecnia na sociedade, e dessa forma caminhar para a consolidação de um projeto educacional com viés marxista, portanto fora dos marcos de uma escola fragmentada, como prevê o pensamento liberal?

\section{Notas}

1 Professor da Faculdade de Educação da Universidade Federal do Rio de Janeiro (UFRJ), Rio de Janeiro, Brasil. Doutor em Educação pela Universidade Federal Fluminense (UFF). < jasantos@globo.com>

Correspondência: Rua Vinte e Quatro de Maio, 99, apto. 406, São Francisco Xavier, Rio de Janeiro RJ, CEP 20950-090.

2 Essa reforma educacional iniciou-se na gestão do ministro da Educação Gustavo Capanema, em 1942, em plena vigência do Estado Novo (1937-1945), com a promulgação da Lei Orgânica do Ensino Industrial, em janeiro de 1942. Foi finalizada pelo ministro da Educação Raul Leitão da Cunha em 1946, já no processo de redemocratização do país, com a edição da Lei Orgânica do Ensino Agrícola, em agosto de 1946.

3 Nos dispositivos legais, instituídos após a promulgação da Lei Orgânica do Ensino Industrial, com o objetivo de reformular o ensino secundário nos diferentes ramos profissionais, a interdição irrestrita aos cursos superiores estava estabelecida da seguinte forma: a) Lei Orgânica do Ensino Comercial - decreto-lei ${ }^{\circ}$ 6.141, de 28 de dezembro de 1943, art. $10^{\circ}$, inciso III; b) Lei Orgânica do Ensino Normal - decreto-lei ${ }^{\circ} 8.530$ de 2 de janeiro de 1946 , art. $6^{\circ}$, inciso 3. Neste caso os concluintes do ensino normal se destinavam às faculdades de filosofia; c) Lei Orgânica do Ensino Agrícola - decreto-lei n 9.613, de 20 de agosto de 1946 , art. $14^{\circ}$, inciso III.

4 Santos (2006), em sua tese de doutorado, ao analisar as bases da construção histórica do projeto societário da ditadura militar (1964-1985), concluiu que, no período 1930-70, a expansão da industrialização no Brasil compreendeu duas fases: a primeira iniciada em 1930 e terminada ao final da década de 1940; e a segunda situada entre o final dos anos 1940 e concluída no início da década de 1970, quando se verificou a crise internacional do capitalismo. Na segunda fase, destacam-se as ações do Estado, tendo como símbolos a criação do Banco Nacional de Desenvolvimento Econômico (BNDE), em 1952, da Petrobras, em 1953, e do Plano de Metas do governo Juscelino Kubitschek (1956-1961), elementos impulsionadores da entrada do capital multinacional no Brasil.

5 A reforma educacional do Estado de Segurança Nacional se fundamentou na Teoria do Capital Humano, formulada por Theodore W. Schultz, a qual se baseava na concepção liberal para pensar a formação humana. Ver Frigotto (1989).

6 A função social do ensino de segundo grau, bem como os seus objetivos estavam fundamentados no documento produzido pelo MEC, sob o título Ensino de $2^{\circ}$ Grau, Formação Profissional e Emprego, logo após a promulgação da lei no 5.692/71. 
7 Mario Manacorda, educador italiano, cuja produção acadêmica no campo da educação se fundamentava em Mar e Gramsci. Dentre as obras do autor, destacamos Para una Interpretación Histórica de la Pedagogia Socialista, texto que fundamentou as análises da autora citada.

8 Dermeval Saviani, ao final da década de 1970, período no qual se desencadeou o movimento de crítica à política de educação implantada pelo Estado de Segurança Nacional, concentrou todos os esforços no sentido de tornar o Programa de Pós-Graduação em Educação na PUC/SP, do qual se tornou coordenador, no centro da produção marxista no campo da educação. Parte do seu grupo de orientandos se constituiu na geração de intelectuais sintonizada com a concepção de politecnia e de escola única, para fundamentar a reforma do ensino de segundo grau na década de 1980. Vários deles se destacaram no mundo acadêmico através da difusão dos seus trabalhos e pesquisas no campo da educação, dos quais se destacam: o próprio Dermeval Saviani, Lucília Regina de Souza Machado, Gaudêncio Frigotto e Acacia Z. Kuenzer. Para mais detalhes sobre o papel do Programa de PósGraduação da PUC/SP na formação dos intelectuais cuja produção acadêmica se alinhava às concepções marxistas, ver Saviani (1997) e Yamamoto (1996).

9 O Congresso Nacional, instituição que exerce o poder legislativo, é formado pela Câmara dos Deputados e pelo Senado Federal. Ver art. 44 da Constituição Federal.

10 Vários educadores da corrente marxista se basearam no trabalho de Antonio Gramsci, Os intelectuais e organização da cultura, para definir a concepção de escola única, explicitada no projeto original de Lei De diretrizes e Bases.

\section{Referências}

AMADO, Gildásio. Educação média e fundamental. Rio de Janeiro: José Olympio, 1973.

ARROYO, Miguel Gonzalez. Sociedade do trabalho e escola de segundo grau. In: Seminário Ensino de Segundo Grau: perspectivas. Anais. São Paulo/SP: Faculdade de Educação da USP, 1988. pp. 36-52.

BRASIL. Decreto-lei no 4.073 de 30 de janeiro de 1942. Lei Orgânica do Ensino Industrial. Disponível: <www.soleis.adv.br/ leiorganicaensinoindustrial.htm $>$. Acesso em: 18 set. 2006 ..

Decreto-lei $\mathrm{n}^{\circ} 4.244$ de 9 de abril de 1942. Lei Orgânica do Ensino Secundário. Disponível em: <www.soleis.adv.br/ leiorganicaensinoindustrial.htm $>$. Acesso em: 18 set. 2006 .

Decreto-lei $\mathrm{n}^{\circ} 6.141$ de 28 de dezembro de 1943. Lei Orgânica do Ensino Comercial. Disponível:<www.soleis.adv.br/ leiorganicaensinoindustrial.htm $>$.Acesso em: 18 set. 2006 .

. Decreto-lei $n^{\circ} 8.530$ de 2 de janeiro 1946. Lei Orgânica do Ensino Normal. Disponível em:<www.soleis.adv.br/leiorganicaensinoi ndustrial.htm>. Acesso em: 18 set. 2006.

Decreto-lei $n^{\circ} 9.613$ de 20 de agosto de 1946. Lei Orgânica do Ensino Agrícola. Disponível em: <http://www.soleis.adv.- 
br/leiorganicaensinoindustrial.htm $>$. Acesso em: 18 set. 2006.

Lei $\mathrm{n}^{\circ} 1.076$ de 31 de março de 1950. Assegura aos estudantes que concluírem curso de primeiro ciclo do ensino comercial, industrial ou agrícola, o direito à matrícula nos cursos clássico e científico e dá outras providências. Disponível em: $<$ www.senado.gov.br/sicon/ExecutaPesqui saLegislacao.action $>$. Acesso em: 10 jul. 2006.

Lei $\mathrm{n}^{\circ} 1.821$ de 12 de março de 1953. Dispõe sobre o regime de equivalência entre diversos cursos de grau médio para efeito de matrícula no ciclo colegial e nos cursos superiores. Disponível em: $<$ www.senado.gov.br/sicon/ExecutaPesqui saLegislacao.action $>$. Acesso em: 10 jul. 2006.

. Lei $\mathrm{n}^{\circ} 3.552$ de 16 de fevereiro de 1959. Dispõe sobre nova organização escolar e administrativa dos estabelecimentos de ensino industrial do Ministério da Educação e Cultura, e dá outras providências. Disponível em: <www.senado.gov.br/sicon/ ExecutaPesquisaLegislacao.action $>$. Acesso em: 10 jul. 2006.

PLC $n^{\circ}$ 1.258. 1988. Fixa as diretrizes e bases da educação nacional. Diário do Congresso Nacional, Brasília, DF, 17 fev. 1988. Seção I, p. 89-98.

. PLC n ${ }^{\circ} 2.784$, de 1989. Fixa as diretrizes e bases da educação nacional. Diário do Congresso Nacional, Brasília, DF, 20 jun. 1989. Seção I, p. 5.104-5.

Substitutivo ao PLC $\mathrm{n}^{\circ} 1258$, do deputado Jorge Hage. Comissão de Educação Cultura e Desportos da Câmara dos Deputados Brasília. Diário do Congresso Nacional, Brasília, DF, 28 jun. 1991, p. 12.

Pronunciamento do deputado Ubiratã Aguiar (PMDB-CE). Diário do Congresso Nacional. Brasília, DF, 1 maio 1991. Seção I, p. 5.057-5.058.
CUNHA. Luiz Antônio. Ensino médio e ensino profissional: da fusão à exclusão. Revista Tecnologia e Cultura, Rio de Janeiro: Cefet, ano 2, n. 2, p. 10-29, jul.-dez. 1998.

FRIGOTTO, Gaudêncio. Formação profissional no $2^{\circ}$ grau: em busca do horizonte da educação politécnica. Cadernos de Saúde Pública, Rio de Janeiro, v. IV, n. 4, p. 435446, out.-dez. 1988.

A produtividade da escola improdutiva: um (re)exame das relações entre educação e estrutura econômico-social e capitalista. 3. ed. São Paulo: Cortez, 1989.

GRAMSCI, Antonio. Os intelectuais e a organização da cultura. 8. ed. Trad. Carlos Nelson Coutinho. Rio de Janeiro: Civilização Brasileira, 1991.

MACHADO, Lucília Regina de Souza. Politecnia, escola unitária e trabalho. 2. ed. São Paulo: Cortez, 1991.

SANTOS, Jailson Alves dos. As bases da reforma do ensino médio e da educação profissional de nivel técnico: as tramas das forças políticas nos bastidores do Congresso Nacional na tramitação da LDB (1988-1996). Tese de doutorado. Rio de Janeiro: Faculdade de Educação, UFF, 2006.

SAVIANI, Dermeval. Política e educação no Brasil: o papel do Congresso Nacional na legislação do ensino. 2. ed. São Paulo: Cortez, 1988a.

Contribuição à elaboração da nova LDB: um início de conversa. Revista da Associação Nacional de Educação, São Paulo: Cortez, n. 13, pp. 5-14, 1988b.

Pedagogia histórico-crítica: primeiras aproximações. 6. ed. Campinas: Autores Associados, 1997.

SOUZA, Paulo Renato de. Carta ao senador Darcy Ribeiro, agradecendo pela votação na Comissão de Constituição e Justiça. Dossiê Darcy Ribeiro. Rio de Janeiro: Fundação Darcy Ribeiro (Fundar), mar. 1995. 
YAMAMOTO, Oswaldo Hajime. A educação brasileira e a tradição marxista (1970-90). Natal: EDUFRN; São Paulo: Moraes, 1996.

Recebido em 06/11/2007 Aprovado em 23/11/2007 